\title{
ARAH BARU PENDIDIKAN ISLAM DI ERA DIGITAL
}

\author{
Shulhan Alfinnas \\ Sekolah Tinggi Ilmu Tarbiyah (STITA) Sumenep \\ shulhan.live@gmail.com
}

\begin{abstract}
This article is aimed to discuss the formulation of Islamic education in digital era and the outcome intended to be gained throughout that education. By emerged digital era explosively, students generally since beginning become native digital, know well how to use digital device properly and easily conversely the majority of adults become digital native who do not really afford utilizing technology. Setting of Islamic education should be designed according to life style of that era's pupils. This treatise is a synthetic though based on liberary research to explore prior findings and thinkings to forulize new terms as respond to the chllange and the opportunity in technology life. There are tow kinds of new synthetic though should be implemented to encourage Muslim generation; digitalizing the subjects of Islamic education and boosting them to reach hasanah in life wheater present and hereafter.
\end{abstract}

Keyword: New Trend, Islamic Education, Digital Era.

\begin{abstract}
Abstrak
Artikel ini dimasudkan untuk membahas tentang formulasi pendidikan Islam di era digital dan outcome yang hendak dicapai dari pendidikan Islam tersebut. Dengan munculnya era digital, pelajar pada umumnya sebagai digital native, sejak lahir langsung mengenal teknologi sahingga sangat mudah bagi mereka untuk menggunakannya berbeda dengan orang dewasa yang kebanyakan menempati posisi sebagai digital migrant. Format Pendidikan Islam harus dirancang sesuai dengan gaya hidup peserta didik era milineal. Tulisan ini merupakan sintesa pemikiran dengan pendekatan library research untuk mengeksplorasi pemikiran dan temuan terdahulu untuk merumuskan pemikiran baru sebagai respon terhadap tantangan dan peluang di era teknologi. Dua hal yang perlu dikembangkan dalam pendidikan Islam yaitu digitaliasi materi yang ajarkan dan mendorang generasi muslim mencapai ke-hasanah-an hidup di dunia dan akhirat. Kata Kunci: Arah Baru, Pendidikan Islam, Era Digital.
\end{abstract}




\section{Pendahuluan}

Era digital merupakan kondisi dimana setiap orang dapat mengakses berbagai infomasi dalam jaringan (daring). Berbagai informasi di era ini tersedia secara bebas di dunia maya yang memudahkan siapa saja untuk mengaksesnya tanpa batas ruang dan waktu. Dunia menjadi tidak ada sekat sama sekali setalah ditemukannya sistem digital. Setiap orang terutama yang lahir sebagai digital native memiliki kecenderungan untuk mencari informasi melalui internet. Mereka lebih suka memanfaatkan fitur-fitur smart phone atau perangkat teknologi lain untuk berselancar di dunia maya baik untuk mencari hiburan atau untuk memenuhi kebutuhan primer. Musik dan dan film dapat dinikmati secara langsung atau diunduh terlebih dahulu secara gratis atau berbayar dengan tarif yang relative murah. Untuk kebutuhan keilmuan dan akses informasi, seseorang bisa medapatkan artikel dengan bebas tanpa persyaratan sama sekali dalam dunia digital.

Fenonema ini di satu sisi adalah hal yang mengembirakan yang menandakan perubahan dunia ke arah yang lebih maju. Dunia digital menawarkan percepatan dalam menyelesaikan berbagai persoalan hidup dan dalam memenuhi berbagai kebutuhan manusia. Dengan system berbasis digital, setiap orang dapat mengurangi ketergantungan (dependence) terhapdap orang lain. Digitalisasi dalam berbagai elemen kehidupan ini memudahkan siapapun untuk mencari informasi dan ilmu pengetahuan dengan cepat tanpa harus pergi ke luar rumah. Dengan bermodal jaringan internet dan perangkat keras (hardwere) dalam berbagai tipe, seluruh umat manusia dapat mewujudkan keinginannya dalam waktu yang relative singkat. Masyarakat sangat terbentuk dan termudahkan dalam berbagai hal dengan ditemukanya dunia digital.

Disisi lain, Teknologi yang dikembangkan oleh ilmuan sebagai basis utama dalam pengoprasian sistem digital menggiring setiap individu untuk menyibukkan diri berkomunikasi dengan dirinya sendiri. Mereka terbawa dalam suasana menikmati berbagai fasilitas yang tersedia di dunia digital. Pemanfaatan sistem digital yang berlebihan menyebabkan masyarakan menjadi individualis. Mereka sibuk dengan hand phone canggihnya dan mengabaikan terhadap keadaan lingkungan di sekitarnya. Duduk berdampingan satu kursi dalam transportasi umum tapi tidak saling bertegur sapa dan tidak saling mengenalkan diri merupakan pemandangan umum dewasa ini di Indonesia. Ini adalah contoh kecil arus dunia digital, mereduksi sensifitas sosial dan kakraban satu 
sama lain. Contoh lain adalah anggota satu keluarga berkumpul dalam satu ruangan tetapi bukan asyik membincangkan satu topic dengan hangat dan penuh keakraban malaikan sibuk dengan gadget masing-masing.

Pendidikan Islam terutama di era digital ini dimaksudkan untuk membentuk generasi muslim yang cakap ilmu dan keterampilan agar mampu melangsung hidup dan baik, aman, sejahatera dan harmonis. Formulasi pendidikan Islam dirancang untuk melatih, dan membina setiap individu muslim agar cakap dalam keimuan islam dan pengamalannya dalam setiap hari dan cakap dalam ilmu praktis berbasis terapan untuk mengelola sumber daya alam sebagai upaya untuk memenuhi kebutuhan sehari-hari. Peserta didik melalui pendidikan ini dididik dalam aspek batin yang berhubungan erat dengan keimanan dan karakter dan juga aspek lahir yang berhubungan dengan keterampilan mencari nafkah sebagai tanggung jawab pribadi untuk mencukupi kebutuhan pokok untuk diri, keluarganya serta masyarakat sekitar yang membutuhkan pertolongan.

Untuk mewujudkan cita-cita luhur tersebut, pegiat pendidikan khususnya yang membidangi pendidikan Islam dituntut untuk mampu memaksimalkan potensi positive yang terdapat dalam dunia digital dan meminimalisir aspek negative yang timbul dari munculnya media tersebut. Pendidik seyogyanya mampu melakukan inovasi design pembelajaran dengan memanfaatkan dunia digital. Kemunculan barang itu yang telah menguasi hampir seluruh dimensi kehidupan anak muda tidak dapat dielakkan lagi. Menjauhkan anak-anak dari bersinggungan dengan dunia maya bukan pilihan yang terbaik tetapi membiarkan mereka terlalu bergantung dengan segala hal yang berhubungana dengan dunia informasi digital tanpa kontrol dan pengarahan merupakan keputusan yang berisiko tinggi. Langkah terbaik adalah memanfaatkannya untuk perkembangan pendidikan mereka dengan menyusuan strategi konten dan model pembelajaran berbasis digital dengan visi besar untuk mewujudkan generasi muslim yang menjangkau ke-hasanah-an hidup.

\section{Digitalisasi Pendidikan Islam}

Kehidupan manusia senantiasa berkembang seiring hasil temuan riset yang dilakukan oleh ilmuan dunia sebagai upaya untuk mengembangkan keilmuan dan untuk menjawab problematika yang terus berkembang di tengah kehiudpan masyarakat global 
atau untuk meningkatkan kualitas hidup manusia secara umum. Salah satu hasil temuan penelitian yang berdampak positif disamping sisi negative yang juga ditimbulkan adalah teknologi informasi. Research discovering ini membawa perubah drastis bagi peradaban dunia dan life style manusia secara umum di dunia. Teknologi telah memenuhi ruang kehidupan manusia terutama yang berada pada fase digital native. Mereka dilahirkan dan membuka mata langsung disambut oleh berbagai jenis teknologi informasi yang booming dan berkembang sangat dinamis. Akhirnya, technology menjadi bagian hidup setiap orang dalam segala aktivitasnya, meskipun pada dasarnya bukan bagian dari kebutuhan primer namun keberadaanya setara dengan kebutuhan pokok manusia native dalam arti mereka tidak dapat terlepas dari ketergantungan pada alat digital.

Fakta ini menuntut pendidik untuk merespon dengan cepat dengan melakukan berbagai terobosan-terobosan program sebagai upaya adjustment dengan baru yaitu era digital. Pendidikan Islam seyogyanya diterapkan dengan pendekatan yang selaras dengan mode dan kecenderungan pelalajar zaman ini. Jika meteri tersebut diajarkan menggunakan metode lama tanpa ada bagian yang terbarukan dikhawatirkan tidak mendapatkan perhatian dan minat yang tinggi dari peserta didik yang berakibat tidak tercapainya target pembelajaran. Kegiatan pembelajaran yang ditetapkan tidak dapat memberikan arti penting dalam membentuk kepribadian dan skill mereka, kegiatan itu hanya berfungsi sebagai kegiatan normatif yang dilaksanakan setiap hari sebagai rutinitas pendidikan tetapi tidak memiliki pengaruh positif karena tidak ada chemistry atau ketertarikan siswa untuk mendalami dan mengamalkannya. Formula pembelajaran hendaknya disesuaikan dengan selera audience dimana mereka sangat mengganderungi dunia digital. Langkah terbaik salah satunya adalah mentransfrormasikan pendidikan islam dalam dunia digital.

The explosion of mobile digital technologies opens up new perspectives to improving educational opportunities, equity and quality. Mobile technology modifies habits of minds; it promotes a new disruptive culture of education and enables services that did not exist before. It has the potential to provide more effective, affordable and scalable educational services to areas where opportunities have been scarce or even absent ${ }^{1}$.

\footnotetext{
${ }^{1}$ Tuuli Tiitola-Meskanen, A Mobile School in the Digital Era Learning Environment Ecosystem Strategies for Challenging Locations and Extreme Poverty Contexts, Proceedings of the 6th Annual Research Symposium in Finland 2014,. 292-304
} 
Munculnya teknologi digital dalam skala besar mampu membuka pandangan baru untuk mengembangkan peluang pendidikan, kesetaraan akses pendidikan bagi siapa saja tanpa diskriminasi. Dunia digital yang bisa dioperasikan dimanapun selama ada jaringan internet dan perangkat keras yang memadai membuka peluang untuk mengembangkan pendidikan secara virtual yang mungkin sebelumnya belum terbayangkan. Dengan munculnya alat ini, pendidikan dapat didistribusikan secara merata tanpa penggunaanya tidak terbatas ruang dan waktu. Mobile technology berhasil dirancang sebagai alat yang dapat mengubah pola pikir manusia. Cara perpikir setiap individu mengalami perubahan drastis dan sulit dikendalikan. Dengan alat ini setiap orang dapat mengekplorasi kemampuan berfikirnya untuk mengembangkan kemampuan diri semaksimal mungkin sehinga jika yang bersangkutan menghasilkan syntesa pemikiran atau produk yg dapat didistribuskan di dunia maya tanpa ada halangan apapun. Device ini memperkenalkan budaya pendidikan yang tidak terkendali dan memungkinan pelayanan pendidikan baru yang belum ada. Alat ini secara potensial menyediakan kemudahan yang lebih efektif, terjangkau dan dapat menjangkau lokasi yang belum tersentuh pendidikan konvensional.

Potensi terbesar dari dunia digital terletak pada aksebilitas non-stop tanpa batasan dimensi ruang dan waktu. Siapapun dapat mencari informasi yang dibutuhkan sesukanya tanpa ada batasan-batasan yang mengikat selama obyek yang dicari tidak bertentangan dengan idealogi negera atau tidak membahayakan masa depan bangsa. Berbagai sumber ilmu pengetahuan disediakan secara gratis dalam dunia digital dari berbagai sumber baik dalam negeri maupun luar negeri. Hal ini salah satu perubahan siknifikan dari munculnya dunia digital. Sebelumnya, pelajar tidak semudah sekarang untuk mendapatkan buku-buku berkualitas dunia. Untuk mendapatkannya kita harus mengeluarkan biaya yang tidak seedikit dan membutuhkan waktu yang cukup. Di saat sytem digital ditemukan semua sumber pendidikan tersedia dengan mudah, cepat dan murah dalam bentuk e-sources seperti jurnal paperless based atau buku elektronik (ebook). Selain itu, dunia digital bagi anak-anak dan pemuda terasa sangat mengasyikkan, selama beberapa jam mereka tidak meresa bosan bermain gadget atau smart phone walau hanya sebatas membukan fitur-fitur yang tidak terlalu penting. Dari sini, pendidik harus mengambil kesempatan untuk memanfaatkan kegandrungan pemuda terhadap 
perangkat digital dan keunggulan dunia digital tersebut dalam menyediakan informasi dan pengetahuan secara real time.

Today's students speak digitally; they are all native speakers of the digital language. If we educators do not take up the challenge to be compatible with students' ability, we will be lagging behind. The worst thing is our role as knowledge disseminator, skill enhancer and value cultivator will be no more significant, since students able to find everything they need outside classrooms but without any guidance ${ }^{2}$.

Peserta didik zaman sekarang mengekspresikan pikirannya secara digital karena mereka lahir sebagai masyarakat asli digital. Berbeda dengan dengan orang tua mereka, yang lahir sebelum terjadinya digitalisasi sistem kehidupan lalu terjadilah revolusi digital yang manuntut mereka hijrah ke dunia teknologi informasi yang mendesaknya untuk menyelesaikan dengan pola baru tersebut dan mengaplikasikanya dalam kehidupan sehari-hari secara pelan-palan dan butuh proses panjang. Jika para pendidikan yang lahir sebagai penduduk pendatang di dunia digital tidak bersiap diri menerima tantangan ini untuk meningkatkan kemampuan pada level yang sesuai dengan kapasitas siswa, mereka akan jauh ketinggalan. Ancaman serius dalam pendidikan Islam adalah tidak signifikannya fungsi guru sebagai kelompok desiminasi ilmu pengetahun, pengembang atau pengasah keterampilan dan penanaman nilai ketika siswa mampu menemukan apa yang dibutuhkan di luar kelas secara mandiri tanpa memerlukan bimbingan expert (ahli). Menyikapi kenyataan ini, pendidikan Islam harus direkayasa sedemikian menggunakan fitur digital yang tersedia selama 24 jam.

Dengan teknik ini, pendidikan dapat mengurangi peluang peserta didik mendapat hal yang dubutuhkan tetepi kualitasnya belum tervalidasi. Contohnya sederhananya adalah saat ini di internet banyak sekali tersedia materi tentang jihat misalnya dari berbagai penulis yang background akademik dan kepakarannya dalam tanda tanya. Jika peserta didik kebetulan mengambil materi yang valid sesuai rujukan-rujukan yang diakui oleh para intelektual tidak perlu dipersoalkan, tatapi jika materi yang didapatkan tidak sesuai dengan rujukan yang digunakan oleh umat islam yang tinggal di Negara ini, potensi penyimpangan prilaku dan pemahaman kemungkinan sangat besar terjadi. Akibatnya sangat fatal seperti terkonstruksinya pola pikir jihadis ala ISIS setelah

\footnotetext{
${ }^{2}$ Wan Noor Hazlina Wan Jusoh dan Kamaruzaman Jusoff, Using multimedia in teaching Islamic studies Journal Media and Communication Studies Vol. 5 no 1 pp. 086-094, November, 2009
} 
menbaca artikel propaganda yang disebarkan dalam jaringan. Langkah taktis untuk mengatasinya adalah materi-materi pendidikan Islam harus digitalisasi yang memungkinkan diakses oleh peserta didik. Proses digitalisasi hendaknya dikelola dengan baik dengan kerja sama dengan digital user yang ahli agar posisi artikel daring tersebut berada paling atas setiap ada orang mencari tulisan dengan kata kunci pendidkan islam atau sejenisnya di Google engine.

Pendidikan konvensional dalam artian tatap muka tetap dibutuhkan untuk eloborasi dan validasi (tashih) terhadap apa yang telah dipelajari peserta didik melalui media online. Membaca materi-materi secara mandiri dalam usia pertumbuhan belajar tidak cukup karena berpotensi salah memahami maksud yang terdapat dalam bacaan tersebut. Hal itu memerlukan bimbingan pendidik untuk meluruskan atau untuk membenarkan.

The intention was to provide an online learning resource designed to appeal to these learners as part of a blended pedagogical approach using face-to-face lectures and tutorials and independent online work. The overall brief was to take the traditional text based face-to-face course and re conceptualize the pedagogy to include the social constructivist principles of learning and an increased use of technology.

Menyediakan sumber belajar secara online dimaksudkan untuk mendukung pesesrta didik menjadi bagian dari kegiatan pembelajaran dengan pendekatan pedagogy campuran yang berupa tatap muka dan tutorial di kelas dan belajar mandiri secara online. Sumber belajar yang tersedia secara digital bermanfaat bagi perserta didik untuk belajar mandiri. Mereka dengan bebas dapat mengontrol diri dan mengukur diri posisi dirinya memahami materi yang dihadapi. Jika belum memahami, murid tersebut dapat mengulang terus pelajaran secara independent sampai pemahamannya dirasa cukup.

Self-study gives students the freedom to control their own learning. Students can learn the difficult topics over and over again until an understanding is reached. Apart from students being the main focus, this learning method requires he support of other factors such as family, educational facilities or the environment is also responsible for self-paced learning ${ }^{4}$.

\footnotetext{
${ }^{3} \mathrm{C}$ Paul Newhouse dkk, Reflecting on Teaching Practices Using Digital Video in Teacher Education, Australian Journal of Teacher Education, Vol 32, No. 3, 2010., 50-62.

${ }^{4}$ Aliff NAWI dkk, Engaging Student Through ICT: Strategies And Challenges For Using Website In Teaching And Learning, International Journal on New Trends in Education and Their Implications July 2014 Vol: 5 Issue: 3 Article: 10 ISSN 1309-6249,. 90-97
} 
Belajar sendiri menggunakan media digital memberikan siswa kebebasan untuk mengontrol pembelajaranya. Mereka dapat mempeleajari topic-topik materi yang sulit dengan berulang-ulang sampai memahami dengan baik. Lingkungn belajaran yang kondusif, fasilitas yang memadai seperti perangkat keras dan akses internet dan dukungan orang tua adalah hal penting untuk mewujudkan program belajar mandiri di luar pelajaran kalas.

Pendidikan diracang untuk memenuhi kebutuhannya dan sebagai jawaban dari apa yang mereka cari sebagai bekal untuk bertahan hidup dan meningkatakan kualitas hidupnya.

Education is not merely to make students know how to read, but to be able to think in a rational manner, knowledge-seeking and know how to survive. To achieve these objectives, the $T \& L$ methods must be innovative and effective for the students of this digital era. Teachers should be wise in using multimedia to meet the expectations of the 'digital smart' students and must be able to combine the teaching and multimedia techniques so that every subjects will comes more interesting and competitive . $^{5}$

Pendidikan tidak semata-mata untuk menjadikan murid mampu membaca tetapi mampu berpikir dengan cara yang rasional, mencari ilmu pengetahun dan mengetahui cara bertahan hidup. Untuk mendapatkan target ini, pembelajaran harus dikemas secara inovatif dan efektif untuk pelajar di era digital ini. Guru harus bijak menggunakan multimedia yang sesuai dengan harapan pelajar dan cakap mengkombinasikan teknik mengajar dan menggunakan media mutakhir sehingga materi pelajaran lebih menarik.

\section{Ke-hasanah-an Hidup}

Pendidikan Islam dimaksudkan untuk mendidik generasi Islam untuk menjadi khalifah Allah di bumi ini dengang baik, penuh tanggung jawab dan menyebarkan perilaku positive terhadap lingkungannya. Pendidikan Islam dirancang dan dijalankan untuk memasukkan nilai spritualitas pada diri peserta didik sampai dipahami secara holistic dan diamalkan secara paripurna dan juga melatihnya untuk terampil mengelola sumber daya alam secara berkesinambungan dan memperhatikan sisi pelestariannya untuk kepentingan jangka panjang (sustainable development).

\footnotetext{
${ }^{5}$ Aliff NAWI dkk, Engaging Student Through ICT: Strategies And Challenges For Using Website In Teaching And Learning, International Journal on New Trends in Education and Their Implications July 2014 Vol: 5 Issue: 3 Article: 10 ISSN 1309-6249., 90-97
} 
"education in Islamic perspective is a process of transferring moral values or knowledge that develops the whole potential of human nature, physically and emotionally with solid and balanced individuals that able to carry out their responsibility as God's caliph on the earth"6.

Pendidikan dalam kaca mata Islam dapat diartikan sebagai sebuah proses transformasi nilai moral dan pengetahuan yang dapat meningkatkan seluruh potensi alamiah manusia baik dari sisi pisik dan emosi secara seimbang yang memungkinkan mereka menjadi pribadi yang bertanggung jawab sebagai khalifah Allah.

Pendidikan anak dalam kerangka pikir umat muslim berarti menyiapkan generasi mendatang untuk benar-benar siap mengemban tugas besar berupa tugas-tugas keagaman secara komprehensip mencakup berbagai dimensi tidak hanya hal yang berhubungan dengan peribadatan saja. "Islamic education is a program which trains the sensibility of pupils in such a manner of attitude to life, action, decisions and approach to all kinds of knowledge. It aims at building the Moslem personality, who has religious sensitivity, social solidarity and scientific methodology".

Pendidikan Islam hendaknya tidak hanya untuk membekali peserta didik pemahaman yang dalam tentang aqidah (keimanan) dan ubudiyah (peribadahan) dan moral serta aplikasinya tetap juga pada saat yang sama mereka dilatih untuk dapat terampil mengelola sumber daya alam yang disediakan oleh Allah di bumi ini. Peserta didik setelah mendapatkan pemahaman dan bimbingan pengamalaman nilai agama Islam dari sisi spiritual dan moral diberikan pendidikan skill yang sesuai dengan kekayakan alam sekitar. Contoh sederhananya, penduduk yang tinggal di daerah dengan potensi alam terbesar adalah pertanian hendaknya mendidik anak-anaknya untuk mempelajari ilmu-ilmu terapan yang berhungan dengan pertanian seperti teknologi pertanian, teknologi hasil pertanian dan teknologi industri pertanian dan sebagainya.

Setting pendidikan seperti ini dimaksudkan sebagai media yang menyiapkan keterampial aktual yang dapat diterapkan langsung ketika selesai studi dan manfaatnya terasa langsung oleh masyarakat sekitar. Dengan kemampuan tersebut, lulusan perguruan tinggi misalnya dapat berkolaborasi dengan masyarakat sekitar dalam meningkatkan kualitas produksi pertanian dan merekayasa olahan pasca panen yang

\footnotetext{
${ }^{6}$ Wan Noor Hazlina Wan Jusoh dan Kamaruzaman Jusoff, Using multimedia in teaching Islamic studies, Journal Media and Communication Studies Vol. 1(5) pp. 086-094, November, 2009

${ }^{7}$ Handoko Ja'far, Indonesian Islamic Education: Towards Science Development, Journal Walisongo, Volume 23, Nomor 2, November 2015, hlm. 331-344
} 
nilai jualnya jauh lebih tinggi dibandingkan hasil panen langsung dijual tanpa kelola terlebih dahulu. Langkah ini akan membantu membangun perkembangan kemandirikan ekonomi rakyat dan membantu masyarakat yang tidak terdidik meningkatkan penghasilnya. Pada saat yang sama, tenaga ahli yang mendapatkan pendidikan sesuai kebutuhan lingkungan dan juga pembinaan penerapan nilai agama menjadi rule model pelaku agama aktif dengan sholat jamaat tepat waktu, puasa suanah, berinfak dan baik terhadap sesama dan alam sekiatar. Lambat laun ini akan menggiring masyarakat sekitar untuk beraktivitas seperti yang dia contohkan. Hal ini mengambarkan pendidikan sesuai kebutuhan real di tengah masyarakat dan dapat mengurai problem yang terjadi di sekitar mereka. Pendidikan agama dalam arti sempit yang hanya mencakup aspek doktrin dan yang berkaitan dengan nilai spiritual belum cukup menjadi jawaban bagi kebutuhan masyarakat kerena jika kebutuhan primer belum terpenuhi mereka susuh menjalankan kewajiban agama.

Pendidikan keterampilan yang sesuai dengan kebutuhan lapangan saja tidak cukup sebagai jawaban untuk mengembangkan manusia menjadi masyarakat madani kerena hanya mampu mengelola alam untuk memenuhi kebutuhan sehari-hari dan belum sepenuhnya mampu menjalankan kewajiban beragama karana kurang pemahaman ilmu agama dan prkatiknya. "Pendidikan islam dimaksudkan untuk dapat menyentuh aspek motoric-fisik manusia. Pendidikan islam berusaha untuk menyiapkan manusia yang memiliki keterampilan fisik yang dapat menopang tuganya sebagai khalifah di permukaan bumi. Selain itu, aspek ruhani manusia merupakan sektor penting yang diperhatikan dalam pendidikan islam ${ }^{8}$. Pendidikan Islam diupayakan dapat menyentuh aspek luar dalam dari manusia secara utuh sehingga mereka dapat menjalankan fungsinya di dunia secara maksimal. Mereka disatu sisi kuat dalam pemahaman agama dan pengamalannya dan disisi lain juga cakap dalam ilmu mutakhir yang erat hubugannya dengan dunia teknologi informasi yang tidak dapat dielakkan dewasa ini.

Guru sejatinya berperan mengantarkan murid untuk mencapai hidup yang hasanah di dunia dan akhirat. Allah SWT membimbing umat manusia agar berusaha untuk mencapainya dengan cara berdoa secara aktif dalam bentuk permohonan lisan dan

\footnotetext{
${ }^{8}$ Shulhan, Konstruksi Filsafat Pendidikan Islam Profetik-Heuristik, Jurnal An Nûr, Vol. VII No. 1 Juni $2015, .87-104$
} 
hati yang di dukung dengan tindakan maksimal ${ }^{9}$. Dalam ayat ini digambarkan bahawa orang mukmin memohon diberikan kebaikan hidup dengan ekspresi kata kerja aatina (mohon didatangkan) bukan a'thina (mohon diberikan). Pemilihan kata ini berimplikasi pada strategi tindakan yang harus dilakukan oleh pemohon. Ia tidak cukup senantiasa memohon terus menurus kepada Allah agar diberikakan kehiduapan yang baik tetapi harus melakukan berbagai aktivitas yang berinilai invitation (undangan) agar Sang Pencinta berkenan mengabulkan apa yang dimaksud pemohon. Undangan tersebut berupa kegiata-kegiatan shalih baik secara langsung (mahdhah) seperti amal-amal ubudiyah yang diwajibkan syariah atau usaha kebajikan lain yang tidak dituntun khusus dalam agama tetapi jika niatnya beribadah terhitung kebajikan (ghairu mahdhah). Selain itu, pemohon juga harus gigih berusaha untuk mewujudkan apa yang diinginkan dengan visi dan program kerja serta target yang jelas. Esensi hidup hasanah bagi umat Islam mencakup tiga unsur yang saling berkaitan. Pertama, menguasai harta, jabatan dan jaringan di dunia.

"In the Islamic system, 'human development is a purposeful activity aiming at: $i$ ) economic development with a fair distribution of benefits, ii) a fair distribution should bring positive change in society, in order that, iii) both these activities of materialistic development should support spiritual development and satisfaction" $" 10$.

Seorang mukmin harus mampu menjadi orang kaya yang kemudian digunakan untuk jalan kebijakan seperti membangun infrastruktur Islam, mendidirikan lembaga pendidikan berbeasiswa dan membangun ekonomi umat. Dengan menguasai jabatan, seseroarang dapat menyusun kebijakan strategis yang menguntungkan dan memihak kepentingan umat Islam tetapi juga tidak merugikan kelompok non muslim. Sederhananya, kepala pemerintahan yang berupa sosok muslim sejati akan berupa mencipatkan kebijakan yang berpihak kepada kepentingan warga yang beragama muslim baik dalam bentuk manfaat langsung maupun tidak langung selama tidak menyengsarakan warga yang beda keyakinan. Jaringan (network) juga dapat digunakan untuk melakukan kemaslahatan bagi umat. Seseorang yang memiliki jaringan ke

\footnotetext{
${ }^{9}$ Al-Quran Surat Al-Baqorah ayat 200

${ }^{10}$ Mumtaz Akhter dkk, Islamic Educational Approach to Environment Protection: A Strategic Approach for Secure and Peaceful World, International Journal of Business and Social Science, Vol. 1 No. 3; December 2010, .182-191
} 
beberapa orang kaya yang muhsin (shalih transformative) dapat menghubungkan pemuda miskin untuk mendapatkan bantuan untuk melanjutkan pendidikan.

Kedua, kaya hati; orang mukmin mutlak harus mampu menjadi aktivator agama. Setiap individu dituntut untuk melaksanakan kewajiban agama dengan baik seperti sholat berjemaah tepat waktu, sholat malam, sholah dhuha, puasa wajib dan sunah. Ia bukan sekedar mampu mendialogkan agama dalam berbagai forum tetapi tidak mampu mempraktikkan langsung dengan istiqomah. "In Islamic philosophy, the main emphasis is on the fact that human beings are composed of 'soul' and 'body' and thus development is required in both these aspects" ${ }^{\text {"11 }}$. Hal ini menyebabkan hati setiap mukim menjadi luas, lembut dan peka terhadap lingkungan. Ketiga, baik terhadap sesama manusia dan lingkungan. Sifat ini hendaknya senantiasa dipupuk dalam diri setiap manusia kerena era digital menggiring setiap orang untuk sendiri-sendiri, apatis dengan lingkungan dan alam. Kekayaan, jabatan dan jaringan seharusnya menjadi capital untuk membantu orang lain agar keluar dari masalah hidup yang membelitnya atau membantunya meningkatkan kualitas hidiup. Disamping itu, kita juga perlu dengan capital tersebut peduli terhadap lingkungan. Alam yang ditempati manusia harus dijaga dan dilindungi dengan baik agar senantiasa memberikan manfaat untuk kelangsungan hidup mansuia itu sendiri.

Ke-hasanah-an hidup ini bisa dijangkau dengan pendidikan yang baik yang mampu mendidik pelajar cakap dalam keterampilan untuk mewujudkan kekayakaan, jabatan dan jaringan dan mampu melaksanakan tugas pokok yang berkaitan langsung dengan agamanya. Teachers stand in the interface of the transmission of knowledge, values and skills in the learning process. If the teacher is in effective, students under the teacher's tutelage will achieve in adequate progress academically. ${ }^{12}$. Guru memiliki peranan vital dalam membangun keilmuan, nilai dan keterampilan peserta didik melalui proses pembelajaran. Peserta didik harus mampu melatih murid untuk mencapi tiga aspek mendasar ini dalam setiap kegiatan pembelajaran. Metode pembelajaran yang

\footnotetext{
${ }^{11}$ Mumtaz Akhter, Islamic Educational Approach to Environment Protection: A Strategic Approach for Secure and Peaceful World, International Journal of Business and Social Science Vol. 1 No. 3; December 2010,.182-191

${ }^{12}$ H. Akhyak, A Study for Searching New Foundation of Philosophy of Islamic Education to Revitalizing the Teacher Roles and Duties in Globalization Era, International Journal of Social Science and Humanity, Vol. 4, No. 5, September 2014.,391-396
} 
efektif yang digunakan oleh guru akan mengantarkan siswa untuk meraih pencapain yang memuaskan. Fokus pembelajaran adalah ilmu, nilai dan keterampilan sebagai dasar untuk mendapatkan level hasanah di dunia dan akhirat. Ilmu adalah pijakan dasar bagi siapapun untuk meningkatkan keterampilan yang kemudian dapat digunakan untuk mengelola kekakayaan alam untuk memperoleh materi. Ilmu juga dalah dasar nilai berketuhanan dan berkemanusian serta berkealaman. Dengan ilmu, seoragan dapat menghamba dengan benar kepada Allah dan berkontribusi positif terhadap lingukungan.

Pendidikan Islam secara mendasar adalah program untuk meningkatkan kepribadian seseorang secara seimbang melalui berbagai kegiatan dan latihan yang berkesinambungan sehingga menjadi sifat yang melekat pada dirinya.

Education should aim at the balanced growth of total personality of man's through the training of man's spirit, intellect of rational self, feeling, and bodily sense. Education should therefore cater for growth of man's in all its aspects, spiritual, intellectual, imaginative, physical, scientific, linguistic, both individually and collectively, and motivate all these aspects toward goodness and attainment of perfection. The ultimate aim of education lies in the realization of complete submission to Allah in the level individual, the community and humanity at large $e^{13}$.

Pendidikan dengan berbagai aktivitas pendidikan harus mampu memberikan nutrisi ilmu dan pelatihan yang sesuai dengan perkembangan dan pertumbuhan seluruh aspek peserta didik dari sisi spiritual, interlektual, fisik, dan bahasa, baik secara individual maupun berjemaah. Anak-anak juga perlu mendapatkan motivasi untuk mencapai prestasi yang sempurna dan meraih kebahagian. Pendidikan bukan kegiatan yang membelenggu tetapi kegiatan yang mengarahkan mereka untuk meraih prestasi terbaik dan juga membahagiakan. Tujuan tertinggi pendidikan adalah untuk mewujudkan penghambaan yang paripurna kepada Allah baik konteks pribadi atau bersama-sama dan cakupan yang luas sehingga meliputi berbagai dimensi antara lain yang berhubungan dengan pengembangan Islam dan keislaman yang itu membutuhkan kekuatan financial, kedudukan dan juga jaringan.

Puncak tertinggi dari pencapaian seseoang di dunia dan akhirat adalah mencapai kebahagiaan. Hal itu bisa diraih dengan cara mengaktulisasikan penghambaan yang tulus kepada Allah swat dengan menjalankan hal disyariatkan agama Islam dengan baik.

\footnotetext{
${ }^{13}$ Wan Noor Hazlina Wan Jusoh dan Kamaruzaman Jusoff, Using multimedia in teaching Islamic studies Journal Media and Communication Studies Vol.5 no 1 pp. 086-094, November, 2009
} 
Selanjutknya kebahagian sesorang mukmin akan semakin lengkap apabila memiliki kemampuan untuk berkontribusi dalam pembangun Islam dan keislaman di sekiatanya. Secara umum, manusia mendapat kontribusi positif dalam wujud materi, kekusaan dan juga sebagai mediasi kebaikan. Semua ini tidak diperoleh serta merta tetapi harus diperjuangkan dengan usaha yang tidak mudah.

Islamic religious education is the process of building and shaping Muslim character that is mu'min (faithful) and muttaqin (devoted) to Allah by emphasising and nurturing values in Islamic teachings so that they will understand Islam and use this knowledge to achieve happiness in the dunya (world) and akhirah (hereafter) ${ }^{14}$.

Umat islam dituntut untuk memahami Islam dengan baik dan menggunakan ilmu dan keterampilannya untuk mencapai kebahagiaan di dunia dan akhirat. Jika ingin mencapi kebahian akhirat, seorang muslim harus menfaatkan kekayaan, jabatan dan harta sesuai ajaran agama dan sebisa mungkin dalam cara yang tergolong amal jariah yang manfaatnya dirasakan lintas generasi. Jika ingin mencapai kebagian dunia, setiap anggota masyarakat muslim harus mampu meraih materi dan tahta sebagi alat untuk memudahkan dirinya mengabdi kepada Allah selama hidupnya.

\section{Kesimpulan}

Pendidikan Isalm di era digital hendaknya dikemas dalam bentuk digital agar sesuai dengan kecenderungan pelajar yang suka menggunakan perangkat digital dalam keseharian. Kebiasaan mereka menggunakan alat teknologi digital adalah cirri khusus masyarakat era digital yang harus dijawab oleh pendidikan untuk menyediakan materi pendidikan dalam perangkat digital agar bisa diakses secara virtual oleh peserta didik. Selain itu, pendidikam Islam yang dilaksanakan harus menjadi kegiatan yang menjembati perseta didik untuk meraih kehidupan yang hasanah di dunia dan akhirat. Indikator orang mencapi level tersebut adalah, menguasai harta, jabatan dan network. Kedua, kaya hati sebagai aktivator agama dalam keseharian dan berbuat baik terhadap sesama serta terhadap lingkungan.

\footnotetext{
${ }^{14}$ Mohd Roslan Mohd Nor and Maksum Malim, Revisiting Islamic education: the case of Indonesia, Journal for Multicultural Education, Vol. 8 No 4, 2014, 261 - 276
} 


\section{Daftar Pustaka}

Akhter, Mumtaz dkk, "Islamic Educational Approach to Environment Protection: A Strategic Approach for Secure and Peaceful World", International Journal of Business and Social Science, Vol. 1 No. 3; December.

Akhyak, H., A "Study for Searching New Foundation of Philosophy of Islamic Education to Revitalizing the Teacher Roles and Duties in Globalization Era", International Journal of Social Science and Humanity, Vol. 4, No. 5, September

Departemen Agama RI. 2009. Al-Qur'an dan Terjemahannya. Surabaya: Duta Ilmu.

Ja'far, Handoko, "Indonesian Islamic Education: Towards Science Development", Journal Walisongo. Vol 23, No 2, November 2015.

Jusoh, Wan Noor Hazlina Wan dan Jusoff, Kamaruzaman. "Using multimedia in teaching Islamic studies". Journal Media and Communication Studies. Vol. 1. No 5. November, 2009

Meskanen,Tuuli Tiitola, A Mobile School in the Digital Era Learning Environment Ecosystem Strategies for Challenging Locations and Extreme Poverty Contexts, Proceedings of the 6th Annual Research Symposium in Finland 2014

Nawi, Aliff dkk, "Engaging Student Through ICT: Strategies And Challenges For Using Website In Teaching And Learning", International Journal on New Trends in Education and Their Implications July 2014 Vol.5. No 3.

Newhouse, C Paul dkk, "Reflecting on Teaching Practices Using Digital Video in Teacher Education", Australian Journal of Teacher Education, Vol 32, No. 3, 2010 .

Nor, Mohd Roslan Mohd dan Malim, Maksum, "Revisiting Islamic education: the case of Indonesia”, Journal for Multicultural Education, Vol. 8 . No 4.2014.

Shulhan, "Konstruksi Filsafat Pendidikan Islam Profetik-Heuristik", Jurnal An Nûr, Vol. VII No. 1 Juni 2015. 